\title{
Schizophrenia in Hollywood Movies
}

\section{Elsayed MA*}

American University of Sharjah, United Arab Emirates

\begin{abstract}
The mentally ill individuals have been significantly portrayed in contemporary Hollywood movies. However literature claims that their awareness to these individuals has not led to positive outcomes because of the extent to which they are stereotyped and negatively presented in movies. This research analyzes twelve movies that are chosen as non-randomly based on the reviews written on them. These movies portray schizophrenic patients between the years 2000- 2012 through quantitative content analysis based on a number of criteria such as demographics, symptoms consistent with DSM-IV-TR, unpredictable behavior, causation and treatment. Surprisingly, 11 out of the 12 movies had schizophrenic patients who were white Americans with either high medium or low socioeconomic status. Delusions and hallucinations were present in all twelve movies (no other positive symptoms were found) and in eight out of twelve movies the patient did not present acts of violence but 10 of the movies showed the character as behaving aggressively. In five out of twelve movies the patient had an exceptional talent and one out of the twelve movies showed that patients got schizophrenia because of a genetic predisposition while seven out of twelve movies showed that the character got the illness because of psychological trauma. It was not mentioned how the patients got the illness in the other four movies. Regarding the treatment that patients received. Moreover, five movies portrayed their patients to be treated by both psychotherapy and medicines while one movie portrayed them as treated with medications alone. In the other six movies there was no reference to the type of treatment that the patients received.
\end{abstract}

Keywords: Movies; Schizophrenia; Mass communication; Stereotype; Negative portrayal; Content analysis

\section{Literature Review}

"What is the natural reaction when told you have a hopeless mental illness? That diagnosis does you in; that, and the humiliation of being there. I mean the indignity you're subjected to my God." Said Kate Millett, a writer and artist, who was referring to the indignity and humiliation one gets exposed to once they get diagnosed with a mental illness [1]. This humiliation is possibly because of the frequent, negative, stereotypical portrayal of mental patients in the media. Diagnosis as referred to by Millet, can put patients in disgrace and fear, not only because of the stigmatized portrayals of the mentally ill but also because of how psychiatric treatments are portrayed in media.

\section{On-screen portrayals of the mentally ill is very frequent}

Media portrayals of the mentally ill individuals are very frequent and potent. It is positive that the media is aware of those individuals to an extent that the abundance of their portrayals can and in fact has become representative of those patients. A research has been conducted examining prime time television programs in the US and results have shown that one-fifth of the programmes represent features of mental illnesses and $2-3 \%$ of the adults are shown as having mental health problems [2]. There were also frequent portrayals of mental illness found in children's movies. A research done in New Zealand proves that half the children (below the age of 10) programmes contain at least one reference to mental illness [2]. Moreover, stereotypical images are also found in Disney animated films. Percentages reveal that referring to mental illnesses verbally was $85 \%$ and $21 \%$ of the characters are referred to as mentally ill [2]. A week rarely passes by without a reference to mental illness globally [3].

\section{Mental illness negative portrayal and stereotypes in media (movies)}

Despite the awareness that is signified through media, their portrayals of mental illness are overwhelmingly negative and distorted. "Movies destroy the idea that mental patients are normal people who can recover and become productive members of the society" [2]. This idea is induced when the symptoms of a mental illness are being presented alone as if this is the character's personality; the illness becomes the only way of defining that person emphasize that patients become defined by the illness in totality, thus being discriminated from others $[4,5]$. Mentally ill patients are more violent than normal people. This is the unreal perspective that media has been reinforcing over and over. The content analysis of movies conclude that the characters whom were labeled as mentally ill were 10 times more violent than the other characters, and based on a two-week programming sample, mental patients are depicted as 10 to 20 times more violent compared to real life psychiatric diagnoses in the U.S. population within an entire year. Plus, one in four mental characters appears as committing either suicide or crime [6]. In other words, they are stereotyped as homicidal maniacs and violent.

A research proved that $55 \%$ of the mental characters were originally shown as victims of abuse, "When pushed too far they became dangerously aggressive and even violent, thus shifting from the victim to the victimizer" [5]. They were almost always poor and/ or homeless and were being held by police for a crime about which they had little recall or understanding of having committed [4]. They are being stereotyped as subjugates who have no family, occupation or social identity or that they are rebellious, ruthless and unruly members who need be cultivated [2]. This is why they are frequently portrayed in situations in which they are irresponsible and need to have someone to make their life decision for them. Byrne believes that mentally ill individuals are "used as substrates for comedy, more usually laughing

*Corresponding author: Elsayed MA, American University of Sharjah, United Arab Emirates, E-mail: g00046456@aus.edu

Received September 17, 2014; Accepted May 06, 2015; Published May 16, 2015

Citation: Elsayed MA (2015) Schizophrenia in Hollywood Movies. J Mass Communicat Journalism 5: 256. doi:10.4172/2165-7912.1000256

Copyright: (c) 2015 Elsayed MA. This is an open-access article distributed unde the terms of the Creative Commons Attribution License, which permits unrestricted use, distribution, and reproduction in any medium, provided the original author and source are credited. 
at than laughing with the characters" [7]. They are viewed in certain movies as objects of amusement, who experience loss of control, derision and fear. Therefore, they should be feared and excluded out of most communities.

Negativity doesn't end there. Infact, many other movies portray mental patients as benevolent, childlike that need to be cared for [8]. Based on a prime-time TV drama analysis, $43 \%$ of the characters who suffered a mental illness lacked comprehension of their roles, were misplaced and disorganized. "Characters typically spoke with grammatically simple language, in a childish voice, and were depicted as helpless and disheveled" said Edney [4]. In movies they tend to avoid discussing the reasons that led to homelessness and this creates the impression that mental patients are dependent on others. Edney concluded the results of the research in which $67 \%$ of mentally ill patients were presented unproductive failures [4]. This is portrayed by lack of employment, nonexistent interactions with family and friends, and by living alone in either broken-down apartments, or on the streets. Moreover, $55 \%$ of the portrayals also enforce lack of social life and positive relationships within the community. "They were, in fact, seen to live on the fringe of the community" said Edney [4].

Mental illness has been viewed similar to prostitution and drug addiction because they are perceived to be in control of their illness and responsible for causing it [8]. In addition, there are a number of different cinematic devices that are used to film the patients' community in movies. For example: "They are filmed alone with closeup or extreme shots, reinforcing their isolation and dislocation from the other characters" said Stuart [2].

\section{Consequences of negative portrayal and stereotyping}

Negative media portrayals go beyond the mental illness to their actual treatment. Studies show that exposure to media that distorts the reality of mental illness cultivates missing information about crime and misconceptions about who committed them. Plus, it stimulates intolerance towards the mentally ill and negatively impacts the public evaluations of mental health issues [2]. Media has also negatively affected the treatment procedures and exaggerated its inhumane effects. For example: "Images of confinement, electric shock and psychosurgery have horrified audiences and even patients" [2]. The over-rated focus on impaired function and behavior endorses gloomy views of psychiatric treatment. Thus, these negative portrayals cause distress to actual real life mental patients and their family members. Stuart, analyzed the responses of family advocates of real life mental patients to conducted surveys. They reported encountering false media representations of the mentally ill and the illnesses that left them feeling angry, hurt, sad and discouraged [2]. This negative portrayal hinders the social performance of patients and affects their treatment and recovery. One third of the actual patients themselves reported that their family and friends treated them differently mainly because of untrue and adverse media coverage. "The expectation that one will be stereotyped because of a mental illness produces social dysfunction and disability that patients are afraid to disclose this fact to others" said Stuart [2].

Moreover, movies attribute negative media imagery for treatment to problems such as denial of symptoms, failed desires to seek treatment and poor devotion to its procedures. Portraying mental health patients as violent and reckless leads the government policies and regulation to work on contaminating, isolating and controlling them than helping them recover and adapt to the community. "If public perception of mental illness is based on negative and false images perpetuated by the media, there is a danger that government responses to systems and people in the mental health field will also be based on these false realities, rather than on the true needs and issues of people suffering from mental illness" said Cutcliffe and Hannigan [3].

\section{How mental health psychiatrists are portrayed by media}

Film presents inaccurate information as well about psychiatric treatments and its authorities. These in accurate depictions affect the credibility of psychiatry in many ways. Psychiatrists are portrayed as "neurotic, unable to maintain professional boundaries, drug- or alcohol-addicted, rigid, controlling, ineffectual, mentally ill themselves, comically inept, uncaring, self-absorbed, having ulterior motives, easily tricked and manipulated, foolish, and idiotic" said Gtinfeld [9]. Edney concluded the results of a number of researches [4]. First is one conducted in the US by U.S. Dept. of Health and Human Services in 1999. The percentage of those mental patients who seek treatment were less than $50 \%$. Second, is a research conducted by Centre for Addiction and Mental Health in 2002 in Canada, in which less than 33\% seek out for treatment. "Depictions of mental health practitioners as exploitative, mentally unstable, and unethical may do irreparable harm to people who are already hesitant to seek treatment, by making the prospect of getting help appear frightening and the help itself appear likely to be ineffective" said Freeman, Edney.

\section{The changing minds campaign}

On the positive side, a number of steps have been taken towards trying to reduce stigma done by the media. The American Psychiatric Association arranges yearly meetings titled 'Overcoming Stigma' since the year 1989. Whatever has been said in these meetings was successively published as a collection of articles. In the year 1999, the Royal College of Psychiatrists' launched a five year Changing Minds anti-stigma campaign [7]. Goffman believes that this is not enough and that for any change to occur, the media should ultimately be the means of any campaign that aims to challenge and replace the stereotypes [10]. Byne believes that the repetitive presence of stigma and the shortage of language to describe its discourse have aided in delaying its transfer since there is no word for the prejudice against mental illness [7]. $\mathrm{He}$ suggested the use of the term 'psychophobic' to describe any individual who continues to hold prejudicial attitudes about mental illness. People who launch campaigns should keep in mind that language has been a key factor in the success of campaigns that oppose discrimination of gender, age, religion, colour, size and physical disability.

Moreover, encouraging an enhanced understanding of the causes of an illness and how it works is likely to reduce stigma [11]. Other scholars such as Huxley recognize that the vital factor is direct contact with people who have had "helpful treatment for episodes of mental illness" or to confront the people who create stigma with their irrational beliefs, in addition to enabling direct contact between a treated patient and a stigmatizer [12]. Bringing this to real life scenarios, the Changing Minds campaign has succeeded in publishing medical journals articles on stigma, clarifying misconceptions of mental illnesses, sorting out stigmas and confronting possible imposers of stigma.

Furthermore, the internet is an extremely effective means of allocating and dispensing information and specific anti-stigma initiatives. Readers can access information about campaigns and their context such as Changing Minds and other sources of evidence that prove stigma wrong. In addition, young children are the decision makers of the next millennium; this is why Wolff suggested listening to the concerns of the people whose attitudes needs to change especially 
young ones and children who have definite fears that need to be acknowledged and addressed [13]. In the latter group, reductions in the levels of fear can be achieved with educational intercessions. Other formal settings, (schools, welfare services, offices) will require the same type of information that would be tailored to their needs. This information includes convincing the target group with the impact of stigma/discrimination, how to challenge the stereotypes within ourselves and others, and follow the continuous task of unscrambling the nature of prejudice.

In conclusion, the on- screen portrayals of mental patients is very frequent in the sense that the media is aware of the members of the society who are mentally ill. However these portrayals are thought to be negative and stereotypical by scholars. These stereotypes created about the mentally ill and how they're treated by psychiatrist have adverse effects on their psychology and their chances of perusing treatment. There have been a number of steps taken and suggested to help reduce the stigma created but there is still doubt if any of them has been effective at all.

\section{Research Question}

\section{To what extend are schizophrenic patients negatively portrayed in movies?}

\section{Methodology section:}

Approach: The approach used in this research is quantitative since the research question looks at the extent to which schizophrenic patients are negatively portrayed in movies. Plus, quantitative approach investigates things that could be observed (such as characters' behaviors and gender in movies). The research is objective, can be repeated by other researchers in a deductive, reductionist manner and it intends to investigate the portrayals in a systemic and empirical way.

Methodology: The methodology used is "content analysis" and is executed by looking at movies that portray mental illness. Content analysis is an objective and systematic quantitative method that analyses messages in which the frequency of negative portrayals will coded statistically. The coding instrument will be adopted from Patricia R. Ownen's research since it overlaps the outcomes to the stated research question. The variables to coding are listed below based on categories. However, three additional features will be added under the sub category unexpected behavior by the researcher based on the reviewed literature.

Demographics. This category looks at gender, race, ethnicity, age range and socioeconomic status. The socioeconomic status will be analyzed based on the character's home which is classified as high, middle, low and undetermined.

Symptoms and stereotypes. This category looks at positive and negative symptoms of schizophrenia that fall in line with DSM-IVTR. It also looks at unpredictable behaviors such as violence or having exceptional talents. Violence in this case is defined by attempting suicide or homicide. The subcategories added by the researcher in this area are aggression, loneliness and drug addiction.

Causation. This category looks at the causes of the illness. It is coded as unstated if the cause is not mentioned in the movie, biological (genetics), environmental (traumatic events) or a combination of both.

Treatment. This category looks at the ways in which the illness is being treated in the movies. The settings for treatment were coded as inpatient (admitted to a hospital) or outpatient (not hospitalized) and the types of treatments are coded as psychological (psychotherapy), biological (medications) or a combination of both (Appendix 1).

Population and sampling: The universal population that will be looked at is Hollywood movies that portray the mentally ill individuals. Based on the research question, what will be looked at is how mental patients are being portrayed in movies. Due to the time limitations, only twelve movies will be analyzed. These movies will fall between the year 2000 and 2012 because this would be the most current and relevant in comparison to our real-life mental health patients. The movies will be chosen non-randomly. Since there are a vast number of Hollywood movies that portray mental patients, analysis will take place only focusing on patients with schizophrenia. There has been a large number of researches focusing on illnesses such as depression, personality disorders and identity disorder but there is very minimal amount of research that looks at how schizophrenia is portrayed. Schizophrenia onset is quite rare for people under 10 years or over 40 years of age. Therefore, the characters (with the mental illness) in the movies should fall between the age group 10 to 40 .

The sampling strategy used is purposive because there are certain criteria that are intended to be considered for the study. Since the sample is not big, the researcher chooses the movies that fit into the criteria mentioned above. The sample used does not necessarily represent the population or intend generalization however; the purpose of the research is to focus on particular characteristics of a population which will help in answering the research questions.

\section{Results and Discussion}

\section{Demographics}

This category looks at the gender, ethnicity, race, age and socioeconomic status. Regarding the gender of the characters who had the schizophrenia 8 out of 12 movies (67\%) presented the patient as a male and 4 movies (33\%) presented the character as a female. This makes a ratio of 2:1. When it comes to race and ethnicity, 11 out of 12 movies (92\%) have the main character as Caucasian and North American while 1 movie out of the $12(8 \%)$ depicts the patient as dark skin toned and African American. The age group lied either within the $30 \mathrm{~s}$ or $40 \mathrm{~s}$. There were 6 out of 12 movies (50\%) that represented the schizophrenic main character to be in their 30s, while 3 out of 12 movies $(25 \%)$ show their main character to be in their 40 s. However, there were outliers. (25\%) of the characters were of the age 27, 14 and 7. According to the reality of the mental illness it is rare for a patient at the age of 7 or even 14 to get diagnosed with schizophrenia. Patients who suffer from schizophrenia can usually be diagnosed with the illness during their early 20 s.

In terms of the characters' socioeconomic status 6 out of 12 movies (50\%) presented the character with a medium socioeconomic status, 4 out of 12 movies $(33 \%)$ show the main character to have a high socioeconomic status and finally, 2 out of 12 movies (17\%) portrayed the patients to be of a low socioeconomic status (living on the streets for example).

The demographics of schizophrenics analyzed in the 12 movies show that the results fall in line with the literature review and the reality of the mental illness. The mental illness fellowship victoria's fact sheets on schizophrenia show that presence of the mental illness is higher in males, in urban communities such as North America. Plus, the fact sheet also concludes that the most common time of onset for males is between 18 and 25 years and for females between 25 years and mid-30s. 


\section{Symptoms and stereotypes}

Under this category, the researcher looks at the symptoms of the illness which are based on the Statistical and Diagnostic Manual of Mental illnesses (DSM-IV-TR). The symptoms that characterize schizophrenia are split into two categories: positive and negative. Positive symptoms are the symptoms that are added to a mentally healthy human's behavior such as hallucinations, delusions and disorientation. While negative symptoms are symptoms that are deducted from a mentally healthy human's behavior such as flat affect and avolition. All the 12 movies (100\%) presented the characters who had schizophrenia to experience hallucinations, only 10 out of 12 movies $(83 \%)$ had the character experience delusions and 4 out of 12 movies (33\%) showed their main character to be disoriented. There were 9 out of 12 movies $(75 \%)$ that did not show the character experiencing any type of negative symptoms. However, 2 out of $12(17 \%)$ movies showed the main characters experiencing flat effect and 1 movie out of $12(8 \%)$ showed the patient experiencing avolition. In contrast to the reality of the mental illness, the symptoms that the characters showed perfectly fit with the symptoms provided in the DSM-IV-TR.

Moving forward to the stereotypes, there were four main categories: violence which is defined by homicide or suicide; Aggression defined by abusive language, throwing or breaking things and screaming; exceptional talent and loneliness. Out of the 12 movies, $4(33 \%)$ presented the patient to be violent, 3 by homicide and 1 by suicide while 8 movies $(67 \%)$ presented the character with no signs of violence. 2 out of the 12 movies (17\%) did not portray any sign of aggression in their patients, while 4 movies (33\%) showed their characters as using abusive language, $2(17 \%)$ as throwing things and $6(50 \%)$ as screaming and shouting. There was an overlap between ones that used abusive language and ones that threw or broke things. For the exceptional talent category, 7 out of 12 movies (58\%) portrayed the patients to have no extraordinary talent while the other $5(42 \%)$ presented their characters to be a mathematician, musician, too brilliant or able to see the future. Finally, when it comes to loneliness 5 movies (42\%) present their character to be lonely and 7 movies (58\%) do not moving forward to drug addiction. Only one movie (8\%) showed the patient as a drug addict while other movies did not. In contrast to the literature review that concludes huge negativity and stereo typicality to the mentally ill individuals, the researcher does not find this conclusion overlapping with the findings of this research. All the 'stereotypes' categories, show that the characters whom are stereotyped are a total percentage of less than $42 \%$. However, what over laps with the literature review is that the patients were all shown to have an aggressive behavior but isn't it right that every human shows aggressive behaviors when they are helpless whether healthy or mentally ill.

\section{Causation}

The third main category looks at what has led to schizophrenia, in other words the causation. The results were very surprising because in reality the mental illness is only caused because of a genetic predisposition. However, only $1 \mathrm{hnjk}$ movie (8\%) out of the 12 acknowledges that, 7 out of the 12 movies (58\%) show the patient to have the mental illness because of an environmental cause or psychological trauma. The seven causes were parents getting killed, losing a daughter, killing their own child and cheating husband, killing own mother, killing own wife, military and an accident. This is where again the movie directors confused the audience between multiple personality disorder and schizophrenia because DID is caused by psychological trauma only while schizophrenia is caused by a genetic predisposition only. There were also 4 movies (33\%) that did not mention at the reason behind the patients' illness.

\section{Treatment}

The fourth and last category looks at the type of treatment they get, whether biological (medicines) or psychological (psychotherapy). Only 1 movie (8\%) presents the patient to be treated with medicines or biologically while the reality of the illness in fact cannot be treated except with medication. None of the movies presented the character to be treated psychologically or with psychotherapy on its own but 5 out of the 12 movies (42\%) showed that their patients were treated by both methods psychologically and biologically. Finally, 6 out of the 12 movies (50\%) did not mention what type of treatment they received (Appendix 2).

\section{Conclusion}

The collected literature claims that the media is quiet aware of mentally ill individuals and that it portrays them in a very negative stereotypical manner. However, this research finds stereotypes in areas such as ethnicity and race but not in violence or drug addiction. The illness is strictly being attached to white North Americans and more to the male community. The level of violence acknowledged in this research was minimal (below 50\%) but aggression was very high. Also, less than $50 \%$ of the characters were portrayed to be lonely. To conclude this research, schizophrenic patients are not so much negatively stereotyped. However, there was a major confusion between the reality of schizophrenia and multiple personality disorder.

\section{References}

1. Millett K (2013) Brainy Quote. Brainy Quote Xplore Web.

2. Stuart $H(2006)$ Media portrayal of mental illness and its treatments: What effect does it have on people with mental illness? CNS Drugs 20: 99-106.

3. Cutcliffe JR, Hannigan B (2001) Mass media, 'monsters' and mental health clients: The need for increased lobbying. J Psychiatr Ment Health Nurs 8: 315321

4. Edney DR (2004) Mass Media and Mental Illness: A Literature Review, Canadian Mental Health Association, Ontario.

5. Wilson C, Nairn R, Coverdale J, Panapa A (1999) Mental illness depictions in prime-time drama: Identifying the discursive resources. Aust N Z J Psychiatry 33: 232-239.

6. Diefenbach DL (1997) The portrayal of mental illness on prime-time television Journal of Community Psychology 25: 289-302.

7. Byrne P (2000) Stigma of mental illness and ways of diminishing it. Journal of Continuous Development.

8. Corrigan PW (1998) The impact of stigma on severe mental illness. Cognitive and Behavioral Practice 5: 201-222.

9. Grinfeld MJ (1998) Psychiatry and mental illness: Are they mass media targets? Psychiatric Times.

10. Goffman E (1986) Stigma: Notes on the Management of Spoiled Identity Engelwood Cliffs, NJ: Prentice-Hall.

11. McGuffin P, Martin N (1999) Behaviour and genes. British Medical Journal 319 37-40.

12. Huxley $P$ (1993) Location and stigma: A survey of community attitudes to mental illness-part 1. enlightenment and stigma. Journal of Mental Health 2: 157-164.

13. Wolff G, Left J (1996) Public education for community care: A new approach Br J Psychiatry 168: 441-447. 